\title{
CAN WE DESIGN AND TEACH TO IMPROVE STUDENT PERCEPTIONS OF "COHORT"?
}

\author{
Tom Whitford \\ Faculty of Business \& Economics, The University of Melbourne \\ Department of Management, 198 Berkeley St, Parkville, 3010, Australia
}

\begin{abstract}
The modern-day university is undergoing major transformations in teaching delivery and design to accommodate massive growth in scale of student enrolments, especially remote learners. Part of this requires a fundamental adjustment to the ways in which we consider the student experience, one of which is the act of dedicated online students participating in a collegial higher-education experience. This is prompted by consistent research highlighting a lack of online student satisfaction in levels of interaction with peers and educators, and an unfulfilling subject experience. This paper will present the ways in which interaction, community, and sociality has been discussed historically in the online learning literature. Finally, it will expand upon this traditional understanding as to how quality learning design(s) could improve cohort experience for the next generation of online learners and instructors alike.
\end{abstract}

\section{KEYWORDS}

Online Learning, Pedagogy, Community, Cohort Management, Distance Education

\section{INTRODUCTION}

Distance education (see also or online learning) continues to grow at a pace globally which affords higher-education institutions the ability to access education markets previously outside their reach (Norton, Cherastidtham 2018). By way of definition, it goes beyond simply a difference in the way content is delivered via instruction, but distinctly the cohort by which is targeted; with their own unique set of learning challenges which require a focus on student support (Webster, Hackley 1997). Due to such scalar growth, online cohorts are larger and student attention competes against various other personal and professional distractions. Indeed, the very idea of "student cohort" is under pressure due to a fragmentation of the student base; acknowledging varying degrees of delivery method in their past educational environments. This has importance for our learning design, which serves to support delivery and achieve comparable student experiences to face-to-face modes (Hannon, D'Netto 2007). Higher education institutions also have responsibilities towards access and equity of student experience, thus to ensure consistency and fairness in this approach to subject offering.

More recent research suggests a return to focusing on cohort experience in online environments (including MOOCs), and the links between performance, participation and attrition (De Freitas et al. 2015). Evidence suggests a positive correlation between peer engagement and improved learning achievement and satisfaction with an online subject (Arbaugh, Duray 2002). Students often indicate a lack of student satisfaction due to the nature of the online spaces designed, and teacher and peer disconnect (O'Shea et al. 2015). The emotional factors of online learning - as reported by student interviews - suggest that cohort's experience of online learning can be anxiously isolating, but ultimately this is resolved as the scheduling is preferable; as it can "fit" to their current lifestyle (Reilly et al. 2012). Most importantly, students have reported intellectual gains, skill mastery, and valid links to their professional practice, which serve to illustrate the promise of well-designed online environments.

This flexibility has been a hallmark of the student preference for learning online, however is not widely replicated in degrees of student motivation. For instructors and teachers alike, a consistent challenge has been how to best manage student cohorts towards a social learning community. Beyond teacher activity, instructional design strategies that involve peers with each other are shown to enhance prosocial communication and interaction (Jaggars, Xu 2016). 
This reflection paper considers a literature review of the notion of "cohort" across the past three decades, and considers foundational learning theories alongside associated constructs such as social presence, sociality, sociability and social space. The paper also proposes some pedagogic strategies to best foster 'cohort', as well as future research directions to support a greater student community.

\section{BODY OF PAPER}

\subsection{Foundational Theories to Assist in our Understanding of "Cohort"}

To situate the literature historically, the corpus on distance education and its subsequent relationship with learning (and, instructional) design accumulates in the late 1990s to early 2000s. This is perhaps characteristic of the ways by which researchers initially conceptualized learners as remote; learning as mediated and isolated, and centered around the phenomena of self-directed or asynchronous instruction. This sense of "space" is further compounded by the rate of technological advancement, which was a prescient concern of Web 1.0 and 2.0 studies (Allen, Seaman 2013).

The late 1980's and early 1990s saw a resurgence in interest for social learning models to explain both offline and the increasing virtualization of education. The links to higher-order thinking were consistent across authors such as Ramsden (1988) and Lipman (1991) who sought to stress the importance on student meaningcreation through robust interaction. Communication and engagement with peers is seen as the epitome of a complete, rich educational experience, and this has been explored thoroughly in classical face-to-face learning settings in the early developmental and educational corpuses.

Bandura's social learning theory soon emerged, which responded to both the classic behaviorist theories (including conditioning) and the importance of the social context (1977). Didactic conversation, and the importance discussion plays in social learning was conceptualized not only between student-student, but also triangulated between content and teacher. This model became foundational for future studies in distance and remote education literatures, and subsequent theories of spatial and relative interaction behaviors, such as transactional distance (Moore 1993).

\subsection{Why Social Learning Works: Defending a Desire for "Cohort" Experiences}

The importance of collaboration emerges around this time as a discourse of its own in the early virtual learning corpus, or what Schrage (1995) describes as shared creation and discovery. In doing so, involving learners in a more active co-construction of knowledge, confirming meaning-making, while going beyond a classic (perhaps, static) view of the importance of student discussion. Gunawardena and Zittle continued the empirical focus on distance education and critical thinking processes (1997). More relevant to this paper, this model proposed a process of negotiation and co-creation of knowledge that included: sharing, dissonance, negotiation, co-construction, application and testing. Once again, the role of peer cooperation and interaction is emblematic of the strong links made between critical-thinking, inquiry-based learning, and social meaning making (between peers) (Wenger, 1998).

Related closely to past notions of collaborative interaction and student motivations to learn is the Community of Inquiry (CoI, henceforth). This now widely-cited model affords a comprehensive description of the ways in which students co-construct a sense of meaning, where shared solutions are sought alongside teachers in a learning environment (Garrison et al. 1999). The CoI offers a baseline to explore online experiences mediated between actors: explaining the social, pedagogic and cognitive interactions which combine towards sense-making and students' understanding for learning. What Garrison and Arbaugh call for is explanation of how social presence creates purposeful connections between peers, and how this evolves and shifts within a CoI (2007). 
Table 1. Historical Taxonomy of Key Constructs in "Cohort" Conceptualisation: Social Presence vs Sociality vs Sociability vs Social Space (as adapted from Lowenthal, Snelson 2017)

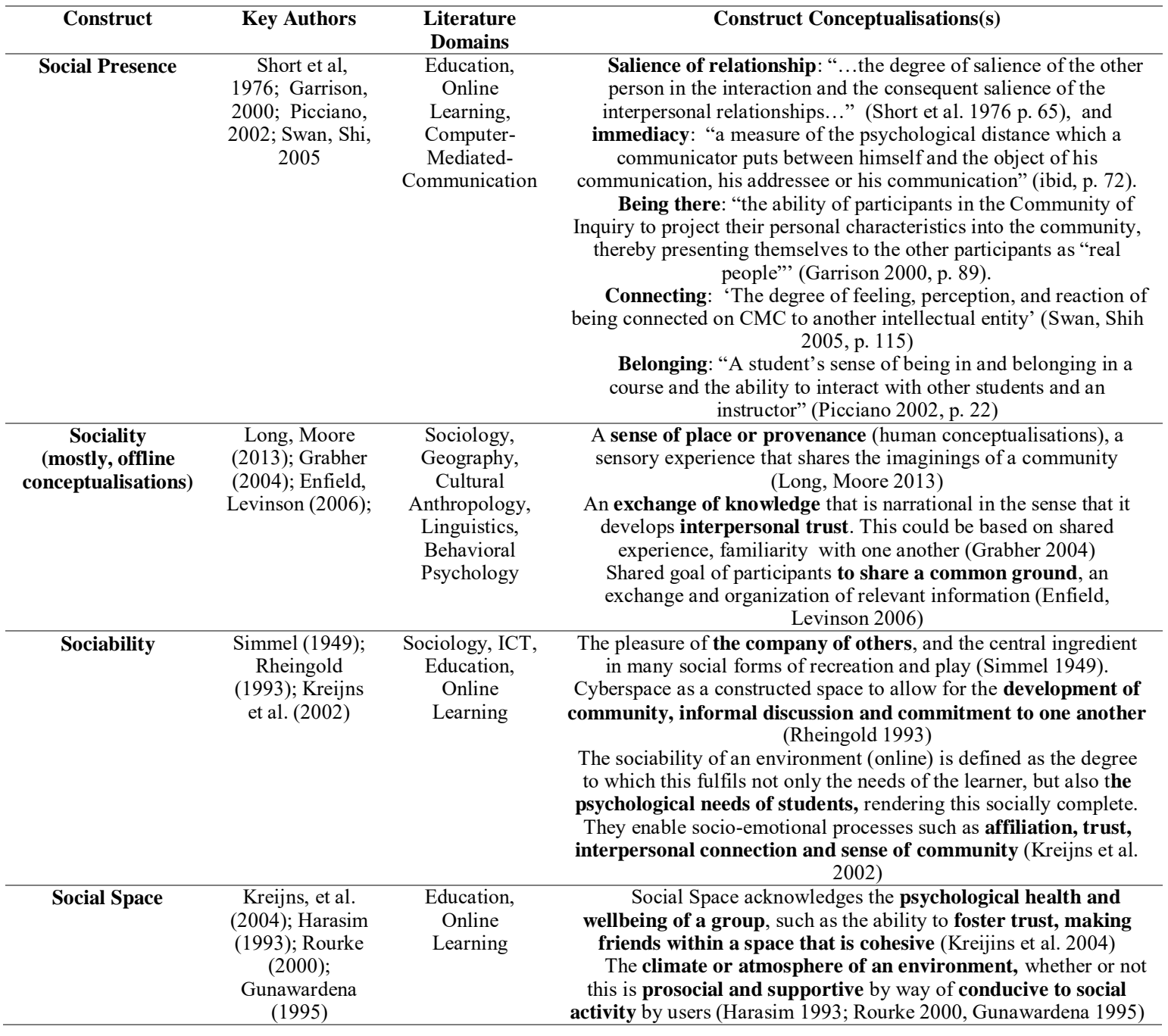

\subsection{Calls to Advance "Cohort" Theoretically: What Next?}

Ebben and Murphy's meta-analyses suggests that with an increased focus and interest in online learning, pedagogy and student engagement, there is a distinct "phase" by which chronologically we can view the work, and how theories of "social" and "cohort" are both used to help inform the literature, and possibly, distract it (2014). Initially, the focus stems from connectivism and engagement, and how we can virtually develop and support inquiry. More recently, we are beginning to see seminal theories to explain cohort - such as social presence - being challenged and compared to other socially-regulated behavioral theories (Mykota 2018). Oztok and Kehrwald challenge the very definitional construct of social presence itself as being relevant to cotemporary online education studies (2017). The authors believe that the breadth of activities and attitudes covered under the umbrella term "social presence", do harm to the analytic ability to study and isolate the phenomena of sociality in virtual spaces.

\subsection{Learning Design Strategies to Address Perceptions of Cohort}

In the MOOC literature, practitioner guides suggest that cohorts can be further engaged with a combination of teaching strategies that include gamification, interactive content, immediacy of feedback, branched 
presentation of content (adaptive), and authentic assessment that encourages reflection (De Freitas et al. 2015). Beyond these explicit approaches to improve student involvement in content, teachers should foremost aim to design spaces that encourage knowledge-sharing between peers.

Suggestions here could include a greater emphasis on team-building activities, as well as relationship development tasks that could include projects that explicitly require collaboration (Tisdale et al. 2004). Jaggers and $\mathrm{Xu}$ note the impact of attaching assessment weightings to forums, showing greater student volume and frequency of engagement and a stronger commitment to perform (2016). More recent research confirms this relationship between immediacy and interactivity being reinforced by appropriate scaffolding, primarily through the use of novel and experimental assessment designs, including peer moderation to further cohort participation (Xia, Fielder, Siragusa 2013). When these deeper and more social approaches to learning are encouraged and supported enthusiastically by teachers and learning designers, a "...love of learning" can be inspired (O’Shea et al. 2015, p. 54).

Teaching delivery that evokes emotional responses, and encourages students relating to each other (personally), and the content to their own lives (perhaps professional), will have a significant determinant on how a sense of cohort is achieved. These emotional factors should be prioritized in our contemporary learning design philosophy; one which both considers student mood, states of mind, and perceptions of peer and teacher support (see Reilly et al. 2012).

Furthermore, a sense of student belonging could be fostered in the design of spaces that represent the physical location of their academic or scholarly communities. Boyer's influential work on campus life distilled the essence of these myriad benefits as "purposeful community" (1990), similar to previous conceptualizations of an academic, or college cohort. Moreover, in the case of online education, it also has been linked to improved retention rates (Hajrasouliha, Ewing 2016). Beyond this representation of the "campus", we should aim to design programs which have consistent groups of students moving through courses and subjects together. This will further encourage a sense of learning community, but also develop participatory behaviors (Engstrom et al. 2008). Here, students will have familiarity with one-another, and faculty staff, where reciprocal and support behaviors tend to follow.

\section{CONCLUSION: FINAL COMMENTS AND FUTURE RESEARCH IMPLICATIONS}

The teaching challenges presented by online and remote learners have been often addressed through intuitive, and often creative, management of our online learning systems. An emergent consideration for cohort understanding is presented by an increased demand for online learning. As this paper proposes, many of these challenges are inherently spatial, with attempts to remove a sense of distance. To be made more aware of the challenges this presents to learning design and teaching is to be aware of the history of the theoretical research on online communities and sociality.

The author calls for us to reflect upon the degree to which 'cohort' is addressed (if at all) in the planning of online education within higher education institutions. Furthermore, are instances of innovation, and pro-social and community-minded learning design and teaching strategies championed within faculties? Do knowledge sharing forums exist within academic departments to better understand "cohort"? These calls require further investigation and empirical support beyond 'best practice'; and should acknowledge the wealth of foundational theory to support positive correlations between social cohorts and quality of learning improvements.

\section{REFERENCES}

Allen, I.E. and Seaman, J., 2013. Changing Course: Ten Years of Tracking Online Education in The United States.

Arbaugh, J. B., \& Duray, R., 2002. Technological and structural characteristics, student learning and satisfaction with

Web-based courses: An exploratory study of two online MBA programs. Management Learning, 33(3), pp. 331-347.

Bandura, A., 1977. Social Learning Theory. Prentice-Hall Englewood Cliffs, NJ.

Boyer, E.L., 1990. "Campus Life: In Search of Community". Carnegie Foundation for The Advancement of Teaching.

De Freitas, S.I., Morgan, J., and Gibson, D., 2015. Will MOOCs Transform Learning and Teaching in Higher Education? Engagement and Course Retention in Online Learning Provision. British Journal of Educational Technology, 46(3), pp. 455-471.

Ebben, M. and Murphy, J.S., 2014. Unpacking MOOC Scholarly Discourse: A Review of Nascent MOOC Scholarship. Learning, Media and Technology, 39(3), pp. 328-345.

Enfield, N. J., \& Levinson, S. C., 2006. Roots of human sociality. New York: Berg. 
Engstrom, M. E., Santo, S. A., \& Yost, R. M., 2008. Knowledge building in an online cohort. Quarterly Review of Distance Education, 9(2), pp. 151.

Garrison, D.R., Anderson, T. and Archer, W., 1999. Critical Inquiry in A Text-Based Environment: Computer Conferencing in Higher Education. The Internet and Higher Education, 2(2-3), pp. 87-105.

Garrison, D.R. and Arbaugh, J.B., 2007. Researching The Community of Inquiry Framework: Review, Issues, And Future Directions. The Internet and Higher Education, 10(3), pp. 157-172.

Grabher, G., 2004. Learning in projects, remembering in networks? Communality, sociality, and connectivity in project ecologies. European urban and regional studies, 11(2), pp. 103-123.

Gunawardena, C.N., 1995. Social Presence Theory and Implications for Interaction and Collaborative Learning in Computer Conferences. International Journal of Educational Telecommunications, 1(2/3), pp.147-166.

Gunawardena, C.N. and Zittle, F.J., 1997. Social Presence as A Predictor of Satisfaction Within a Computer-Mediated Conferencing Environment. American Journal of Distance Education, 11(3), pp. 8-26.

Hajrasouliha, A.H. and Ewing, R., 2016. Campus Does Matter: The Relationship of Student Retention and Degree Attainment to Campus Design. Planning for Higher Education, 44(3), pp.30.

Hannon, J. and D'Netto, B., 2007. Cultural Diversity Online: Student Engagement with Learning Technologies. International Journal of Educational Management, 21(5), pp. 418-432.

Harasim, L. M., 1993. Networlds: Networks as Social Space. In L.M. Harasim (Ed.) Global Networks: Computers and International Communication (pp. 15 - 34). Cambridge, MA: MIT Press.

Jaggars, S.S. and Xu, D., 2016. How Do Online Course Design Features Influence Student Performance? Computers \& Education, 1(95), pp. 270-284.

Kreijns, K., Kirschner, P. A., \& Jochems, W. 2002. The sociability of computer-supported collaborative learning environments. Journal of Education Technology \& Society, 5(1), pp 8-22.

Kreijns, K., Kirschner, P. A., Jochems, W., \& Van Buuren, H, 2004. Determining sociability, social space, and social presence in (a) synchronous collaborative groups. CyberPsychology \& Behavior, 7(2), pp.155-172.

Lipman, M., 1991. Thinking in Education. Cambridge University Press, Cambridge.

Long, N. J., \& Moore, H. L. (Eds.)., 2013. Sociality: new directions (Vol. 1). Berghahn Books.

Lowenthal, P. R., \& Snelson, C. (2017). In search of a better understanding of social presence: An investigation into how researchers define social presence. Distance Education, 38(2), 141-159.

Moore, M.G., 1993. The Theory of Transactional Distance. Theoretical Principles of Distance Education. Routledge: London, pp. 84-103.

Mykota, D., 2018. The Effective Affect: A Scoping Review of Social Presence. International Journal of e-Learning \& Distance Education, 33(2), pp.2.

Norton, A. and Cherastidtham, I., 2018. Mapping Australian Higher Education 2018. The Grattan Institute, Melbourne.

O'Shea, S., Stone, C. and Delahunty, J., 2015. “I 'Feel'like I Am at University Even Though I Am Online.” Exploring How Students Narrate Their Engagement with Higher Education Institutions in an Online Learning Environment. Distance Education, 36(1), pp. 41-58.

Oztok, M. and Kehrwald, B.A., 2017. Social Presence Reconsidered: Moving Beyond, Going Back, Or Killing Social Presence. Distance Education, 38(2), pp. 259-266.

Picciano, A.G., 2002. Beyond student perceptions: Issues of interaction, presence, and performance in an online course. Journal of Asynchronous Learning, 6(1), pp. 21-40.

Ramsden, P., 1988. Improving Learning: New Perspectives. Nichols Pub Co.

Reilly, J.R., Gallagher-Lepak, S. and Killion, C., 2012. "Me and My Computer": Emotional Factors in Online Learning. Nursing Education Perspectives, 33(2), pp. 100-105.

Rheingold, H., 1993: The Virtual Community: Homesteading on the Electronic Frontier. Cambridge, MA: MIT Press.

Rourke, L., 2000. Exploring Social Communication in Computer Conferencing. Unpublished Master Thesis. Alberta, Edmonton Alberta.

Schrage, M., 1995. No More Teams! Mastering The Dynamics of Creative Collaboration. New York: Doubleday.

Short, J., Williams, E., Christie, B., 1976. The social psychology of telecommunications John Wiley \& Sons, Ltd, Hoboken, NJ

Simmel, G., \& Hughes, E. C., 1949. The sociology of sociability. American journal of sociology, 55(3), pp.254-261.

Swan, K., \& Shih, L. F., 2005. On the nature and development of social presence in online course discussions. Journal of Asynchronous learning networks, 9(3), pp.115-136.

Tisdell, E. J., Strohschen, G. I., Carver, M. L., Corrigan, P., Nash, J., Nelson, M., \& O'Connor, M., 2004. Cohort learning online in graduate higher education: Constructing knowledge in cyber community. Journal of educational technology \& society, 7(1), pp.115-127.

Webster, J. and Hackley, P., 1997. Teaching Effectiveness in Technology-Mediated Distance Learning. Academy of Management Journal, 40(6), pp. 1282-1309.

Wenger, E., 1998. Communities of Practice: Learning, Meaning, and Identity. Cambridge University Press.

Xia, C., Fielder, J. And Siragusa, L., 2013. Achieving Better Peer Interaction in Online Discussion Forums: A Reflective Practitioner Case Study. Issues in Educational Research, 23(1), pp. 97-113. 